\author{
Charles L. Sprung \\ Robert Cohen \\ Bruria Adini
}

\title{
Chapter 1. Introduction
}

(C) Copyright jointly held by Springer and ESICM 2010

On behalf of the European Society of Intensive Care Medicine's Task Force for Intensive Care Unit Triage during an Influenza Epidemic or Mass Disaster.

\section{L. Sprung (『)}

Department of Anesthesiology and Critical Care Medicine, Hadassah Hebrew University Medical Center,

Jerusalem, Israel

e-mail: charles.sprung@ekmd.huji.ac.il

\section{R. Cohen}

Israeli Ministry of Health,

Faculty of Medicine, Hebrew University,

Tel Aviv, Jerusalem, Israel

\section{B. Adini}

Israeli Ministry of Health, Ben-Gurion

University of the Negev, Tel Aviv,

Beersheba, Israel
Abstract Background: In December 2007, the European Society of Intensive Care Medicine established a Task Force to develop standard operating procedures (SOPs) for operating intensive care units (ICU) during an influenza epidemic or mass disaster. Purpose: To provide direction for health care professionals in the preparation and management of emergency ICU situations during an influenza epidemic or mass disaster, standardize activities, and promote coordination and communication among the medical teams.

Methods: Based on a literature review and contributions of content experts, a list of essential categories for managing emergency situations in the ICU were identified. Based on three cycles of a modified Delphi process, consensus was achieved regarding the categories. A primary author along with an expert group drafted SOPs for each category. Results: Based on the Delphi cycles, the following key topics were found to be important for emergency preparedness: triage, infrastructure, essential equipment, manpower, protection of staff and patients, medical procedures, hospital policy, coordination and collaboration with interface units, registration and reporting, administrative policies and education. Conclusions: The draft SOPs serve as benchmarks for emergency preparedness and response of ICUs to emergencies or outbreak of pandemics.

Keywords Recommendations · Standard operating procedures . Intensive care unit · Hospital · H1N1 . Influenza epidemic - Pandemic . Disaster
In December 2007, the European Society of Intensive Care Medicine established the Task Force for Intensive Care Unit (ICU) Triage during an Influenza Epidemic or Mass Disaster to develop recommendations and standard operating procedures (SOPs). At this time worldwide intensive care, infectious disease/microbiology, pulmonary and nursing societies were contacted to send representatives to participate. Society representatives from intensive care (Society of Critical Care Medicine, Australia and New Zealand Intensive Care Societies, Canadian Critical Care Society, American Thoracic Society, American College of Chest Physicians, Chinese Critical Care Society, Colombia Intensive Care Society, Scottish Intensive Care Society, Singapore Critical Care Society and the UK Intensive Care Society), infectious disease/microbiology (European Society of Clinical 
Microbiology and Infectious Diseases, Infectious Diseases Society of America, British Infection Society and the French Infectious Disease Society) and pulmonary disease (French Respiratory Society) have been involved in the project from its initiation. The Task Force consists of experts in intensive care medicine, microbiology/ infectious diseases, nursing, epidemiology, public health, medical engineering and ethics. The initial idea was that the recommendations and standard operating procedures (SOPs) would be relevant for any disaster that would create an increased demand for hospital beds, a demand that would be difficult to meet. A procedure described below was developed to provide consensus for the final recommendations and SOPs. Although the procedure has not ended, the potential for a severe H1N1 pandemic outbreak in the upcoming winter months in the Northern hemisphere and the demands such an outbreak will create for ICU resources led the Task Force to immediately publish the recommendations and SOPs in their present state. The following chapters present the recommendations and SOPs of the key topics identified and developed by the Task Force, stressing points relevant to H1N1. A summary of these recommendations has been published as a review [1]. The information should also be helpful for other hospital areas and other types of emergency scenarios including mass casualty events. Search terms used for the literature review are shown in Appendix 1. The author's first-hand experience with emergency responses is found in Appendix 2.

Preliminary information regarding H1N1 patients is available. Approximately $8 \%$ of H1N1 patients are hospitalized [2, 3] (23 per 100,000 population) [4]; $6.5-25 \%$ of these require being in the ICU $[2,4,5]$; $(28.7$ per million inhabitants) [6] for a median of 7-12 days [6,7] with a peak bed occupancy of 6.3-10.6 per million inhabitants [6]; 65-97\% of ICU patients require mechanical ventilation $[3,6-8]$ with median ventilatory duration in survivors of $7-15$ days $[5,7,8] ; 5-22 \%$ require renal replacement therapy $[6,7]$, and 28-day ICU mortality is $14-40 \%[5,7,8]$.

\section{Standard operating procedures (SOP)}

Health care professionals in many countries have recognized the need to develop plans or programs to respond to both man made and natural emergencies and disasters $[9,10]$. A SOP is a set of written instructions that describe a routine or repetitive activity that is performed in an organization [11]. SOPs are viewed as the basis for efficient management of all types of emergencies and are an integral part of a successful quality system as they provide guidance to the staff on how to perform a job properly and facilitate consistency of actions $[10,11]$.
A hospital SOP defines the specific procedures, precautions and equipment needed for management of emergencies, and provides guidelines and protocols for the hospital to plan its response, prepare the infrastructure required and train medical teams [9, 12]. It has been repeatedly demonstrated that preplanning saves time, facilitates integrated efforts and helps ensure that essential activities are carried out efficiently [13].

It is important to recognize that the availability of an SOP in itself does not guarantee efficient and effective functioning of personnel and the organization during an emergency. In order for an SOP to be effective, it should be periodically updated, and the personnel involved in managing an emergency should be trained how to utilize it [14]. The aim of this project was to develop recommendations and SOPs for the effective operation of ICUs during an influenza epidemic or mass disaster. The materials focus on the ICU, but are also helpful for the hospital.

\section{Purpose of the SOPs}

SOPs provide direction for the medical personnel to manage the emergency situation [15]. The SOPs establish the minimum acceptable performance criteria for dealing with the emergency and are aimed at outlining standards that are fair and equitable for all who choose to adopt them [16]. An SOP defines the legal basis for emergency management activities, outlines the authority and organizational relationships during emergency situations, and describes how actions should be coordinated. The SOP assigns responsibilities to the organizations and individuals for carrying out specific emergency actions to protect lives; to identify personnel, equipment, facilities, supplies and other resources available for use during response and recovery operations; to define prevention and response actions to reduce threats and damages and to outline procedures to expand surge capacities and reinforce resources [13]. The SOP defines the performance expectations for personnel, provides a benchmark for evaluating the operational performance, and helps to standardize activities and promote coordination and communication among the medical teams [17].

\section{SOP development}

In developing the SOPs, the following process was implemented [16, 18]. Based on a literature review and contribution of content experts, a listing of essential categories and subcategories for which SOPs would be developed were identified. A modified Delphi process was 
used by the Task Force members to obtain consensus regarding the categories and subcategories and rate their importance. Task Force members voted for the major categories by agreeing, disagreeing or modifying them and rating their level of importance as essential, important or not important for inclusion. They were also requested to add categories that might impact on the emergency preparedness and that they believed were missing. Categories for which $80 \%$ or more of the raters agreed on the level of importance were defined as having achieved "consensus" and warranted inclusion in the study. Categories that did not receive this level of consensus were returned to the Task Force members with a request that they modify them in such a way that would be rated as important or that they be discarded as a category. A total of three Delphi cycles were conducted. Following the completion of the third Delphi cycle, agreement was reached that the following categories are important for emergency preparedness: triage, infrastructure, essential equipment, manpower, protection of staff and patients, medical procedures, hospital policy, coordination and collaboration with interface units, registration and reporting, administrative policies and education. Following the consensus for determining the categories and subcategories to be included in the SOPs, each category was assigned a primary author and expert group to draft the SOPs for that category. The drafted materials were then sent for review and comments to task members in order to map consensus and determine which elements were not agreed upon. To date, an organized poll of the entire task force for each chapter has not yet been implemented. Similar modified Delphi cycles will be conducted in order to approve each specific part of the chapters. As chapters for hospital policy, registration and reporting and administrative policies have not yet been written, important factors for those chapters have been incorporated in the present chapters. The chapters are presented in the order one might prepare their hospital for a disaster or H1N1 pandemic outbreak.

\section{Conclusions}

These SOPs have been developed to provide guidance in the preparation and management of a mass disaster or disease outbreak. This guidance should be used as a framework to guide the development of detailed systems and processes at local facilities. The detailed guidelines for frontline use should therefore be a product of the SOP, local situational awareness and the specific threat faced. Even in the setting of H1N1, assumptions based on previous H1N1 data may change based on the present deployment of effective vaccines, viral mutations and resistance to antiviral drugs such as neuraminidase inhibitors for which the H1N1 virus is presently sensitive [6]. Known data are evolving rapidly and should result in appropriate responses and changes in frontline guidelines. Such changes will be necessary because preparations must occur as soon as possible. "Any deaths from 2009 influenza A (H1N1) will be regrettable, but those that result from insufficient planning and inadequate preparation will be especially tragic [19]."

Conflict of interest None.

\section{Appendix 1: Search terms used for the literature review}

1. Standard operating procedures-"SOPs," "protocols of emergency management," "doctrines of emergency preparedness," "guidelines of emergency preparedness and response."

2. Surge capacity-('surge capacity' and 'critical care') and ('surge capacity' and 'hospitals') and ('disaster medicine' and 'critical care').

3. Coordination and collaboration-A. Key words"coordination OR collaboration" AND "outbreak OR pandemic OR epidemic OR emergency." B. Internet search-coordination and collaboration, each matched with each of outbreak, pandemic, epidemic and emergency. C. Targeted review of websites-World Health Organization (WHO), Centers for Disease Control and Prevention (CDC), Center for Health Protection [CHP (HK)], Hospital Authority [HA(HK)], US Department of Health and Human Services (HHS.gov and flu.gov), Australian Government Department of Health and Ageing, Department of Health $[\mathrm{DH}(\mathrm{UK})]$ and European Centre for Disease Prevention and Control (EDDC).

4. Manpower-PubMed, Google, Google scholar, Bing and Yahoo using the following search terms: disaster, disaster preparedness, disaster planning, staff, manpower, altered standards of care, staff shortage, pandemic influenza, critical care, incident command, ventilator stockpiling, vaccination, mass vaccination and antiviral administration. Additional searches included personal contact with the following agencies: US Department of Health and Human Services (ASPR, BARDA), the Centers for Disease Control and Prevention, US Department of Homeland Security, California Department of Public Health, California Emergency Medical Services Authority, Institute of Medicine, American College of Chest Physicians, American Thoracic Society and the Society for Critical Care Medicine.

5. Equipment, pharmaceuticals and supplies-variations of equipment, ventilators, pharmaceuticals, drugs, medications and supplies with intensive care, critical care, disaster, epidemic, influenza and H1N1. 
6. Protection of patients and staff-no specific search strategy was used for this project. Searches were used for previous committees including "critical disaster planning, H5N1 staff protection, SARS - protection for health care workers, staff morale in SARS, psychosocial care for health care staff, personal protective equipment in a pandemic, PPE in SARS, fit-testing for N95 respirators, reducing airborne infection in hospitals, medico-legal implications of pandemic, implications of triaging in Hurricane Katrina and health care workers attitudes to working in a pandemic."

7. Critical Care triage-no specific search strategy was used for this project. Searches were used for previous publications and committees.

8. Medical procedures-pandemic, influenza, procedures, SARS, disaster planning and intensive care.

9. Educational process-staff education AND pandemic influenza AND training AND education AND preparation in various combinations. Also SARS AND staff education; SARS AND staff training. (CG-"SARS" AND "training OR in service training").

\section{Appendix 2: Author's first-hand experience with emergency responses}

Charles Sprung Experience ICU director for many multiple casualty terror events. Participant in hospital exercises for biological and chemical warfare. Publications Shamir MY, Weiss YG, Willner D, Mintz Y et al. (2004) Multiple casualty terror events: the anesthesiologist's perspective. Anesth Analg 98:1746-1752; Aschkenasy-Steuer G, Shamir M, Rivkind A et al. (2005) Clinical review: the Israeli experience: conventional terrorism and critical care. Crit Care 9:490-499; Shamir MY, Rivkind A, Weissman C, Sprung CL, Weiss YG (2005) Conventional terrorist bomb incidents and the intensive care unit. Curr Opin Crit Care 11:580-584; Pizov R, Oppenheim-Eden A, Matot I et al. (1999). Blast lung injury from an explosion on a civilian bus. Chest 115:165-172. During mass casualty events in Israel, administrators and dentists have provided added manpower by working in the ICU.

Janice L. Zimmerman Experience Supervised trainees in Houston in providing health care in the aftermath of Hurricane Katrina; supervised ICU functioning and staffing during Hurricane Ike; current member of the H1N1 work group and Emergency Management Work Group for The Methodist Hospital and member of the Texas Pandemic Influence Medical Ethics Work Group for the Department of State Health Services.

Michael D. Christian Experience Has been involved with disaster medicine for over 20 years, initially with his
Incident Command training as a paramedic. Over the years he has responded to emergencies small and large. Most recently he was involved in both the clinical response to SARS in Toronto as well as participating on investigative and research teams. He has served in both expert and leadership roles in government disaster and pandemic planning. Academically Dr. Christian has been very active in the field of emergency preparedness conducting research as well as teaching others about emergency preparedness and disaster management. Publications Christian MD, Poutanen SM, Loutfy MR, Muller MP, Low DE (2004) Severe acute respiratory syndrome. Clin Infect Dis 38:1420-1427; Christian MD, Kollek D, Schwartz B (2005) Emergency preparedness: What every healthcare worker needs to know. CJEM 7:330-337; Christian MD, Hawryluck L, Wax RS et al. (2006) Development of a triage protocol for critical care during an influenza pandemic. CMAJ 175:1377-1381; Christian MD, Devereaux AV, Dichter JR, Geiling JA, Rubinson L (2008) Definitive care for the critically ill during a disaster: current capabilities and limitations: from a Task Force For Mass Critical Care summit meeting, 26-27 January 2007, Chicago, IL. Chest 133(5 Suppl):8S-17S; Christian MD, Sandrock CE, Devereaux A, Geiling J, Amundson DE, Rubinson L (2009) Ethical issues and the allocation of scarce resources during a public health emergency. Ann Intern Med 150:890-891.

Gavin Joynt Experience In 2003 served as the Director of a 22-bed ICU managing in excess of 70 SARS cases in a 3-month period during the SARS outbreak in Hong Kong and was a member of the Hospital Executive Crises Committee during the SARS outbreak in Hong Kong. He was also a member of the Central Operations Committee, Hospital Authority (COC, HA) during the period 20012005 and during the 2003 SARS outbreak in Hong Kong. Publications Lee N, Hui D, Wu A et al. (2003) A major outbreak of severe acute respiratory syndrome in Hong Kong. N Engl J Med 348:1986-1994; Gomersall CD, Joynt GM, Ho OM, Ip M, Yap F, Derrick JL, Leung P (2006) Transmission of SARS to healthcare workers. The experience of a Hong Kong ICU. Intensive Care Med 32:564-569; Gomersall CD, Tai DY, Loo S et al. (2006) Expanding ICU facilities in an epidemic: recommendations based on experience from the SARS epidemic in Hong Kong and Singapore. Intensive Care Med 32:10041013; Gruber PC, Gomersall CD, Joynt GM (2006) Avian influenza (H5N1): implications for intensive care. Intensive Care Med 32:823-829; Gomersall CD, Loo S, Joynt GM, Taylor BL (2007) Pandemic preparedness. Curr Opin Crit Care 13:742-747.

John Hick Experience (1) Has served as a member of the AHRQ workgroup on mass medical care with scarce resources, and the American College of Chest Physicians (ACCP) workgroup on Emergency Mass Critical Care 
(EMCC) as well the Institute of Medicine's Guidance for Establishing Crisis Standards of Care for use in Disaster Situations. (2) Based on his experience he has published widely on hospital surge capacity and has served as a consultant to Health and Human Services (HHS) on scarce resource situations. Personal responses include $35 \mathrm{~W}$ bridge collapse, 2008 Republican National Convention and $2009 \mathrm{H} 1 \mathrm{~N} 1$ events with consultative services provided to HHS during and after Hurricane Katrina. Publications Hick JL, Danila R (2001) Health care planning for chemical and biologic terrorism. Minn Med 84:34-40; Hick JL, Hanfling D, Burstein JL, Markham J, Barbera J, Mcintyre AG (2003) Personal protective equipment for healthcare facility decontamination personnel: regulations, risks, and recommendations. Ann Emerg Med 42:370-380; Hick JL, Penn P, Hanfling D, Lappe MA, Olaughlin D, Burstein JL (2003) Establishing and training healthcare facility decontamination teams. Ann Emerg Med 42:381-390; Hick JL, Hanfling D, Burstein JL, DeAtely C, Barbisch D, Bogdan G, Cantrill S (2004) Healthcare facility and community strategies for patient care surge capacity. Ann Emerg Med 44:253-261; Hick JL, O'Laughlin DT (2006) Concept of operations for triage of mechanical ventilation in an epidemic. Acad Emerg Med 13:223-244; Hick JL, Rubinson L, O'Laughlin DT, Farmer JC (2007) Clinical review: allocating ventilators during large- scale disasters: problems, planning, and process. Crit Care 11:217 (e-published June 11, 2007); Devereaux AV, Dichter JR, Christian MD et al. (2008) Definitive care for the critically ill during a disaster: a framework for allocation of scarce resources in mass critical care: from a Task Force for Mass Critical Care summit meeting, 26-27 January 2007, Chicago, IL. Chest 133:51S-66S; Rubinson L, Hick JL, Curtis JR et al. (2007) Task Force for Mass Critical Care. Definitive care for the critically ill during a disaster: medical resources for surge capacity: from a Task Force for Mass Critical Care summit meeting, 26-27 January 2007, Chicago, IL. Chest 133(5 Suppl):32S-50S; Rubinson L, Hick JL, Hanfling DG et al. (2008) Task Force for Mass Critical Care. Definitive care for the critically ill during a disaster: a framework for optimizing critical care surge capacity: from a Task Force for Mass Critical Care summit meeting, 26-27 January 2007, Chicago, IL. Chest:133:18S31S; Hick JL, Chipman J, Loppnow F et al. (2008). Hospital response to a major freeway bridge collapse. Disaster Med Public Health Prep 2:S11-S16; Hick JL, Ho JD, Heegaard WG, Brunette DD, Lapine A, Ward T, Clinton JE (2008) Emergency medical services response to a major freeway bridge collapse. Disaster Med Public Health Prep 2:S17-S24; Hick JL, Koenig KL, Barbisch D, Bey TA (2008) Surge capacity concepts for health care facilities: the CO-S-TR model for initial incident assessment. Disaster Med Public Health Prep 2:S51-S57; Hick JL, Barbera JA, Kelen GB (2009) Refining surge capacity: conventional, contingency and crisis capacity.
Disaster Med Public Health Prep. (e-published ahead of print April 6, 2009 as doi:10.1097/DMP.0b013e31 819f1ae2, print June 2009).

Bruce Taylor Experience (1) Chaired the UK Critical Care Contingency Planning Group, producing guidelines for capacity expansion and Critical Care Infection Control available on the United Kingdom (UK) Department of Health (DH) website (2005-2007) and provided critical care advice to DH Pandemic Influenza Planning groups (2005-2009). (2) Since the H1N1 outbreak he has been involved with the DH sentinel data collection group (FLU-CIN), Pandemic Influenza Clinical and Operational advisory group and Swine Flu Critical Care Clinical Group, and was charged with responsibility for addressing high-priority clinical implications. (3) He has contributed to H1N1 national clinical guidance on critical care practice, pediatric intensive care, expanding pediatric intensive care services, and secondary care for H1N1 infected patients (adults, children and pregnant women). He has produced documentation for support of NHS Staff Working in Exceptional Circumstances in order to help maintain or expand existing services (available www.ics.ac.uk).

Guy Richards Experience Director of the 18-bed ICU/ HCU Johannesburg Hospital. Personal experience dealing with H1N1, Ebola and Lassa. Publications Richards GA (2007) Avian influenza: the looming threat. Clin Pulm Med 14:212-216; Richards GA (2006) Avian influenza: preparation not panic. Prim Care Respir J 15(4):217-218; Richards GA (2006) The threat of a new influenza pandemic: are we doing enough? S Afr Med J 96:195-196; Paweska JT, Sewlall NH, Ksiazek TG et al. (2009) Nosocomial outbreak of novel arenavirus infection, Southern Africa Emerg Infect Dis 15:1598-1602; Richards GA, Murphy S, Jobson R, Mer et al. (2000) Unexpected Ebola virus in a tertiary setting: clinical and epidemiologic aspects. Crit Care Med 28:240-244; Richards GA, Sewlall NH, Duse A (2009) Availability of drugs for formidable communicable diseases. Lancet 373:545-546.

Christian Sandrock Experience (1) Is a physician with expertise in infectious diseases and pulmonary and critical care medicine. He specializes in disaster preparedness, emerging infectious diseases, terrorism and other threats to public health. (2) As medical director of the California Preparedness Education Network (a Health and Human Services Funded Program), he has developed educational materials, primarily for providers in rural, border, innercity and underserved areas of the state. (3) He served as the medical director of the Hospital Bioterrorism Preparedness Program for the state of California and currently serves as the medical adviser to the state Emergency Medical Services Authority. He contributes his expertise to the US Centers for Disease Control and Prevention, Hospital Bioterrorism Preparedness Program, 
and many other Homeland Security projects. (4) He is the principal investigator in the Emergency Care Partnership Program, a $\$ 5$ million grant evaluating the role of force multiplication in disaster settings by using telemedicine and critical care standards. (5) He is currently the Director of the Intensive Care Unit at the University of California, Davis, where he has implemented a number of response measures for $\mathrm{H} 1 \mathrm{~N} 1$, including altered standards of care, manpower alteration, mass vaccination and ventilator stockpiling and planning. (6) He is involved in a number of professional societies and federal disaster preparedness initiatives, including the disaster section co-lead for the American Thoracic Society. He has responded to local disasters in California and the Western United States and carried out relief work in Africa over the past 10 years.

Robert Cohen Experience (1) Recently retired from the Hebrew University Faculty of Medicine, Centre for Medical Education, where he served as Chairman. Currently serves as a senior educational consultant with the Emergency Medicine Division of the Israel Ministry of Health developing a tool for the evaluation of hospital preparedness to deal with mass casualty events. (2) He is also currently a senior researcher at the Israel National Center for Trauma \& Emergency Medicine Research at Tel Hashomer Hospital. (3) He has worked with Operations Division of Magen David Adom to improve the Continuing Education programs for Emergency Medicine Technicians (EMTs). (4) He developed an assessment program to evaluate the effectiveness of educational interventions, knowledge based tests and performance assessment for EMTs. (5) He participated in the development of courses for the World Health Organization and the Emergency Medicine Division of the Israel Ministry of Health for physicians from Eastern Europe, the Balkan states and Italy on preparedness for disasters and mass casualty events.

Bruria Adini Experience (1) Served in the Medical Corps of the IDF for 17 years. In her last post she served for 4 years as the head of the emergency hospitalization branch (responsible for the emergency preparedness of all general hospitals for emergencies). (2) For 3 years she served as the head of the Emergency Hospitalization and Alert Department in the Ministry of Health. (3) Since 2000, she has served as senior consultant to the Ministry of Health for preparedness of medical systems for emergencies. (4) She is currently a faculty member of the Emergency Medicine Department in the Ben-Gurion University of the Negev. Since 1987 she has specialized in emergency preparedness of health care systems for dealing with mass casualty events and disasters. She has acquired extensive experience in issuing national operational doctrines, SOPs and protocols for various types of emergency events and scenarios; medical manpower management and operation; planning, developing and conducting training programs, including instructive materials, such assimulation exercises and drills. (5) She has developed tools for evaluating readiness; training personnel from Israel and from other countries in developing and enhancing emergency preparedness. (6) Dr. Adini has a $\mathrm{PhD}$ in management of health systems. Her thesis focused on development of an evaluation tool to assess the level of emergency preparedness of acute-care hospitals to emergencies and disasters. Publications Adini B, Goldberg A, Cohen R, Bar-Dayan Y (2008) Relationships between standards of procedures (SOPs) for pandemic flu and level of performance in drill. Ann Emerg Med 52:223-229; Adini B, Goldberg A, Laor D, Cohen R, Bar-Dayan Y (2007) Factors that may influence the preparation of standards of procedures for dealing with mass-casualty incidents. Prehosp Disaster Med 22:175-180; Adini B, Goldberg A, Laor D, Cohen R, BarDayan Y (2007) Staff procedure skills in management groups during exercises in disaster medicine. (Editorial review) Prehosp Disaster Med 22:322-324; Adini B, Goldberg A, Laor D, Cohen R, Zadok R, Bar-Dayan Y (2006) Assessing levels of hospital preparedness for emergencies. Prehosp Disaster Med 21:451-457.

Shi Loo Experience (1) Director of ICU Services in the National SARS ICU in the designated SARS Hospital in Singapore during the SARS Outbreak 2003; (2) Director of ICU Services during Epidemics, Tan Tock Seng Hospital, Singapore; (3) Chairman, National Workgroup for ICU Response in Epidemics, Ministry of Health, Singapore.

Gila Margalit Experience (1) Chief Nurse for Mass Casualty Planning, Sheba Medical Center; (2) worked as Head of Hospital Preparedness for Emergency Scenarios branch, responsible for overall readiness of all general hospitals in Israel; (3) conducted more than 75 hospital drills for HAZMAT, Mass Casualties, Radiology, Chemical and Biological Warfare; (4) Head Nurse of the Israeli Field Hospital, and Aid Delegation following an earthquake in Turkey (1999). Publications Margalit G, Rosen Y, Tekes-Manova D et al. (2002) Recommendation for nursing requirements at a field hospital based on the Israel Defense Forces field hospital at the earthquake disaster in Turkey-August 1999. Accid Emerg Nurs 10:217-220.

Jozef Kesecioglu Experience Director of a 32-bed multidisciplinary intensive care department at the University Medical Center Utrecht. The department of intensive care has close relations with the National Institute for Public Health and the Environment, which covers research and advice on new infectious diseases, protection against infectious diseases through vaccination and risks due to poisonous substances and exposure to radiation. Publications de Jonge E, Schultz MJ, Spanjaard L, Bossuyt PM, Vroom MB, Dankert J, Kesecioglu J (2003). Effects of selective decontamination of digestive 
tract on mortality and acquisition of resistant bacteria in intensive care: a randomised controlled trial. Lancet 362:1011-1016; Verbrugge SJ, Lachmann B, Kesecioglu J (2007) Lung protective ventilatory strategies in acute lung injury and acute respiratory distress syndrome: from experimental findings to clinical application. Clin Physiol Funct Imaging. 27:67-90; Kesecioglu J, Beale R, Stewart TE, Findlay GP, Rouby JJ, Holzapfel L, Bruins P, Steenken EJ, Jeppesen OK, Lachmann B (2009) Exogenous natural surfactant for treatment of acute lung injury and the acute respiratory distress syndrome. Am J Respir Crit Care Med 180:989-994.

John R. Colvin Experience (1) Critical care representative on the UK Departments of Health Committee on
Ethical Aspects of Pandemic Influenza; (2) Chair of the Scottish Critical Care Delivery Group co-coordinating capacity building, prioritization plans and triage frameworks for Scottish government pandemic influenza planning; (3) critical care member and co-author of the UK Departments of Health report on 'Pandemic influenza-Managing Demand and Capacity in Health Care Organisations (surge); (4) member of UK Departments of Health Swine Flu Critical Care Clinical Group and Subgroup on ECMO provision; (5) Regional Health Board lead for Critical Care with responsibility for regional pandemic influenza contingency planning; (6) consultant in Intensive Care Medicine providing critical care for patients with $\mathrm{H} 1 \mathrm{~N} 1$ disease.

\section{References}

1. Sprung CL, Zimmerman JL, Christian MD et al (2009) On behalf of the European Society of Intensive Care Medicine's Task Force for intensive care unit triage during an influenza epidemic or mass disaster.

Recommendations for intensive care unit and hospital preparations for an influenza epidemic or mass disaster. Summary report of the European Society of Intensive Care Medicine's Task Force for intensive care unit triage during an influenza epidemic or mass disaster. Intensive Care Med (in press)

2. Jain S, Kamimoto L, Bramley AM et al (2009) Pandemic Influenza A (H1N1) Virus Hospitalizations Investigation Team (2009) Hospitalized patients with 2009 H1N1 influenza in the United States, April-June 2009. N Engl J Med 361:1935-1944

3. Echevarría-Zuno S, Mejía-Aranguré JM, Mar-Obeso AJ et al (2009) Infection and death from influenza A H1N1 virus in Mexico: a retrospective analysis. Lancet 374:2072-2079

4. Bishop JF, Murnane MP, Owen R (2009) Australia's Winter with the 2009 pandemic influenza $A(\mathrm{H} 1 \mathrm{~N} 1)$ virus. $\mathrm{N}$ Engl J Med 361:2591-2594

5. Dominguez-Cherit G, Lapinsky SE, Macias AE et al (2009) Critically ill patients with 2009 influenza $\mathrm{A}(\mathrm{H} 1 \mathrm{~N} 1)$ in Mexico. JAMA 302(17):1880-1887

6. The ANZIC Influenza Investigators (2009) Critical Care Services and 2009 H1N1 influenza in Australia and New Zealand. N Engl J Med 361:1925-1934
7. Rello J, Rodriguez A, Ibanez $\mathrm{P}$ et al (2009) Intensive care adult patients with severe respiratory failure caused by Influenza A $(\mathrm{H} 1 \mathrm{~N} 1) \mathrm{v}$ in Spain. Crit Care 13:R148. doi:10.1186/cc8044

8. Kumar A, Zarychanski R, Pinto R et al (2009) Canadian Critical Care Trials Group H1N1 Collaborative. Critically ill patients with 2009 influenza $\mathrm{A}(\mathrm{H} 1 \mathrm{~N} 1)$ infection in Canada. JAMA 302(17): 1872-1879

9. Joint Commission on Accreditation of Healthcare Organization (2009) Accreditation Program: Hospital. Pre-publication version. Available at: http://www.canainc.org/compendium/ pdfs/D\%201.\%20JC\% 20Standards\%202010.pdf

10. Simon R, Teperman S (2001) The World Trade Center Attack. Lessons for disaster management. Crit Care 5:318-320

11. Quarentelli EL (1985) Organizational behavior in disasters and implications for disaster planning. Disaster Research Center, University of Delaware, Newark, DE 1985

12. Davis LM, Blanchard JC Are local health responders ready for biological and chemical terrorism? Available at: http://www.rand.org/pubs/issue_papers/ IP221/index 2.htm

13. Barbera JA, Yeatts DJ, Macintyre AG (2009) Challenge of hospital emergency preparedness: analysis and recommendations. Disaster Med Public Health Prep 3(2 Suppl):S74-S82
14. Western Australia (2008) State Emergency Management Plan for the management of emergencies associated with a structural collapse. Available at: http://www.bing.com/ search?q=7.6.\%09Western+Australia $+\% 282008 \% 29$.+State+ Emergency+Management + Plan + for + the + management + of + emergencies + associated + with $+\mathrm{a}+$ structural+collapse \&src $=$ IE-SearchBox\&FORM=IE8SRC

15. Emergency Management Accreditation Program (2007) Emergency management standard. Available at: http://www.oregonemergency.com/ docs/principles_of_em.pdf

16. Federal Emergency Management Agency (1999) Developing effective standard operating procedures. Available at: http://www.usfa.dhs.gov/downloads/ pdf/publications/fa-197.pdf

17. Adini B, Goldberg A, Cohen R, BarDayan Y (2008) Relationships between standards of procedures (SOPs) for pandemic flu and level of performance in drill. Ann Emerg Med 52(3):223-229

18. Pill J (1971) The Delphi method: substance, context, a critique and an annotated bibliography. Socioecon Plann Sci 5:57-71

19. White DB, Angus DC (2009) Preparing for the sickest patients with 2009 influenza A (H1N1). JAMA. doi:10.1001/jama.2009.1539 